\title{
Management of intracranial aneurysms associated with arteriovenous malformations
}

\author{
Bruno C. Flores, M.D., ${ }^{1}$ Daniel R. Klinger, M.D. ${ }^{1}$ Kim L. Rickert, M.D., ${ }^{1,2}$ \\ Samuel L. Barnett, M.D., ${ }^{1}$ Babu G. Welch, M.D., ${ }^{1,2}$ Jonathan A. White, M.D., ${ }^{1,2}$ \\ H. Hunt Batjer, M.D., ${ }^{1}$ And Duke S. SAmson, M.D. ${ }^{1}$
}

Departments of ${ }^{I}$ Neurological Surgery and ${ }^{2}$ Radiology, University of Texas Southwestern Medical Center, Dallas, Texas

\begin{abstract}
Intracranial or brain arteriovenous malformations (BAVMs) are some of the most interesting and challenging lesions treated by the cerebrovascular neurosurgeon. It is generally believed that the combination of BAVMs and intracranial aneurysms (IAs) is associated with higher hemorrhage rates at presentation and higher rehemorrhage rates and thus with a more aggressive course and natural history. There is wide variation in the literature on the prevalence of BAVM-associated aneurysms (range $2.7 \%-58 \%$ ), with 10\%-20\% being most often cited in the largest case series. The risk of intracranial hemorrhage in patients with unruptured BAVMs and coexisting IAs has been reported to be $7 \%$ annually, compared with $2 \%-4 \%$ annually for those with BAVM alone. Several different classification systems have been applied in an attempt to better understand the natural history of this combination of lesions and implications for treatment. Independent of the classification used, it is clear that a few subtypes of aneurysms have a direct hemodynamic correlation with the BAVM itself. This is exemplified by the fact that the presence of a distal flowrelated or an intranidal aneurysm appears to be associated with an increased hemorrhage risk, when compared with an aneurysm located on a vessel with no direct supply to the BAVM nidus. Debate still exists regarding the etiology of the association between those two vascular lesions, the subsequent implications for patients' risk of hemorrhagic stroke, and finally the determination of which patients warrant treatment and when. The ultimate goals of the treatment of a BAVM associated with an IA are to prevent hemorrhage, avoid stepwise neurological deterioration, and eliminate the mortality risk associated with recurrent hemorrhagic events. The treatment is only justifiable if the risks associated with an intervention are lower than or equivalent to the long-term risks of disability or mortality caused by the lesion itself. When faced with this difficult decision, a few questions need to be answered by the treating neurosurgeon: What is the mode of presentation? What is the symptomatic lesion? Which one of the lesions bled? What is the relationship between the BAVM and IA? Is it possible to safely treat both BAVM and IA? The objective of this review is to discuss the demographics, natural history, classification, and strategies for management of BAVMs associated with IAs.
\end{abstract}

(http://thejns.org/doi/abs/10.3171/2014.6.FOCUS14165)

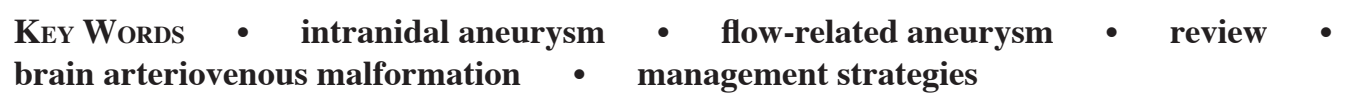

I NTRACRANIAL or brain arteriovenous malformations (BAVMs) are some of the most interesting and challenging lesions treated by the cerebrovascular neurosurgeon. They are associated with intracranial aneurysms (IAs) in a higher incidence than in the general population,

\footnotetext{
Abbreviations used in this paper: ARUBA = A Randomized Trial of Unruptured Arteriovenous Malformations; AVM = arteriovenous malformation; $\mathrm{BAVM}=$ brain AVM; IA = intracranial aneurysm; $\mathrm{IVH}=$ intraventricular hemorrhage; NPPB $=$ normal perfusion pressure breakthrough; SRS = stereotactic radiosurgery.
}

and the coexistence of these vascular lesions is well documented in the literature. $3,7,9,10,12,13,23,33,36,38,41,45,47,60,64,76,77$ It is generally believed that the combination of BAVMs and IAs is associated with higher hemorrhage rates at presentation and higher rehemorrhage rates, thus being associated with a more aggressive course and natural history.

Credit is given to Laves, in 1925,42 and Stewart and Ashby, in $1931,{ }^{74}$ for the first anatomopathological description in two separate case reports. The first clinical case report was published by Walsh and King in $1942 .{ }^{80}$ Since then, a multitude of articles have followed, but debate still 


\section{B. C. Flores et al.}

exists regarding the etiology of the association of BAVMs and IAs, the subsequent implications for patients' risk of hemorrhagic stroke, and finally the determination of which patients warrant treatment and when. Such controversy was accentuated by recent prospective studies showing hemorrhage rates as low as $1 \%$ per year for unruptured BAVMs. ${ }^{23,71}$ The publication of the A Randomized Trial of Unruptured Arteriovenous Malformations (ARUBA) data, ${ }^{54}$ with evidence favoring medical management alone over interventional management in unruptured BAVMs, adds one more data point to the controversy involving supporters of both a more conservative or more aggressive approach.

The objective of this review is to discuss the demographics, natural history, classification, and strategies for management of AVMs associated with IAs.

\section{Epidemiology}

Ruptured BAVMs account for approximately $2 \%$ of all hemorrhagic strokes ${ }^{19,25}$ nonetheless, they represent a significant medical and social burden that typically affects otherwise healthy young adults. ${ }^{59,61}$ The BAVM detection rate reported in a recent random-effects metaanalysis was 1.31 per 100,000 person-years. ${ }^{19}$ There is wide variation in the literature on the actual prevalence of BAVM-associated aneurysms (range 2.7\%-58\%), with a prevalence of $10 \%-20 \%$ being most often cited in the largest case series., $3,9,10,12,13,41,45,48,51,64,77$ Independent of source, there is consensus that the incidence of aneurysms associated with BAVMs is greater than that of aneurysms in the general population (which has been estimated at $2 \%$ of adults without risk factors for subarachnoid hemorrhage $[\mathrm{SAH}]),{ }^{65}$ a pattern that cannot be solely explained by random association. The Cooperative Study of Intracranial Aneurysms and Subarachnoid Hemorrhage estimated that $1.4 \%$ of patients with an IA had a coexistent BAVM ${ }^{61}$ Several factors, such as a variable definition of aneurysms, the sensitivity of various diagnostic imaging studies to detect associated vascular lesions, the type of catheter angiography (selective vs superselective), and sampling error due to referral patterns, can help explain those discrepant numbers.

The incidence of BAVMs associated with aneurysms does not appear to differ based on sex; however, women may be more likely to present with hemorrhage. ${ }^{10,76}$ The average age at presentation is approximately 40 years. Nonetheless, the number of IAs appears to correlate positively with age, with one study reporting that $8 \%$ of the BAVMs diagnosed before the patient was age 25 years, $24 \%$ of those diagnosed in patients between age 25 and 50 , and $37 \%$ of those diagnosed in patients after age 50 had associated IAs. ${ }^{41}$ Multiple IAs can be found in as many as $26 \%-51 \%$ of the cases. . $^{72,16,35,41,58,76,79}$

\section{Natural History}

Before advances in neuroimaging and the widespread availability of MRI, virtually all patients with BAVMs would present symptomatically, approximately two-thirds of them after hemorrhage. An unruptured BAVM has an overall 2\%-4\% yearly risk of hemorrhage. ${ }^{25,59,81}$ The mortality rate after a first hemorrhage is about $10 \%$, and the risk of major disability is $20 \%-30 \% .{ }^{81}$ In his review of the natural history of BAVMs, Wilkins reported a $6 \%$ chance of rebleeding during the 1st year and $2 \%-3 \%$ rehemorrhage rate thereafter up to 20 years. ${ }^{81}$ Two of the largest contemporary prospective studies evaluating the natural history of symptomatic BAVMs did not include the presence of associated aneurysms in their statistical analyses. ${ }^{25,59}$ However, they provided unpaired data and their follow-up periods represented the longest for untreated patients available in the literature. Ondra et al. prospectively followed 166 untreated symptomatic patients with BAVMs for a mean period of 23.7 years. The rate of major rebleeding was $4 \%$ per year, and the mortality rate was $1 \%$ per year. The mean interval between initial presentation and rehemorrhage was 7.7 years. At follow-up review, 23\% of their patients were dead due to BAVM hemorrhage. ${ }^{59}$ Hernesniemi et al. later expanded that series to 238 patients, for whom the revised overall annual rupture rate was $2.4 \%$. The risk of a hemorrhagic event was higher during the first 5 years $(4.6 \%)$ than thereafter $(1.6 \%){ }^{25}$

Although the aforementioned studies provide an interesting assessment of the overall demographics of BAVMs in a relatively stable and homogeneous population, the numbers reported in those papers appear to be a misrepresentation of the actual risk for BAVMs associated with IAs. Brown et al. reported hemorrhage rates as high as $7 \%$ per year at 5 years for patients with coexisting BAVMs and aneurysms, compared with $1.7 \%$ hemorrhage rate per year for patients with BAVMs alone. ${ }^{9}$ Adequate confirmation of the hemorrhage source was not possible in the majority of the patients with BAVMs and IAs, but the authors believed the higher hemorrhage risk reflected rupture of coexisting aneurysms. In one of the most important longitudinal studies about the natural history of IAs and other vascular malformations, $7.6 \%$ of the study population with a diagnosed BAVM had coexisting aneurysms, ${ }^{61,81}$ with a hemorrhage rate at presentation for this cohort that was higher than the overall study population. More recently, the ARUBA trial reported an incidence of $16 \%$ of associated aneurysms in the study cohort, with no correlation to the hemorrhage at presentation or at followup completed on their initial data analysis. ${ }^{54}$

Three main theories have been proposed to better explain the association between BAVMs and IAs. The coincidental theory was initially published by Boyd-Wilson ${ }^{8}$ and assumed that the coexistence of those two vascular lesions was an incidental finding. The congenital theory, put forth by Arieti and Gray, ${ }^{4}$ defended a common congenital, genetically determined vascular etiology for both BAVMs and IAs. The hemodynamic theory was developed by McKissock and Paterson ${ }^{50}$ and has become increasingly popular. It suggested that the increased blood flow due to the presence of the BAVM might result in increased abnormal stresses on major feeding vessels and thus predispose to aneurysm formation. A hemodynamic relationship between increased blood flow and aneurysm formation is also supported by case reports of internal carotid artery aneurysm formation following contralateral carotid artery ligation. ${ }^{67}$ It is important to emphasize that these are not 
mutually exclusive theories; in fact, an interaction between congenital and hemodynamic causes appears to be a reasonable explanation for the majority of the reported cases.

Several authors have attempted to identify clinically significant risk factors associated with increased BAVM hemorrhage risk. Marks et al. identified 3 characteristics that correlated positively with hemorrhage: central venous drainage, periventricular or intraventricular location of the BAVM, and intranidal aneurysm. ${ }^{47} \mathrm{~A}$ subsequent study from the same authors showed $100 \%$ history of bleeding in patients with intranidal aneurysms diagnosed by catheter angiography. ${ }^{48}$ Histological evaluation of 2 pathological specimens showed those intranidal aneurysms to be thin-walled vascular structures rather than pseudoaneurysms, and the aneurysms were believed to be the likely source of BAVM hemorrhage. Similar results were published by Redekop et al., with hemorrhagic presentation significantly more common in the subgroup with intranidal aneurysms $(72 \%)$ than in the entire BAVM population without aneurysms $(36 \%)$ or the subgroup of patients with aneurysms elsewhere (40\%). ${ }^{64}$ Their $9.8 \%$ per-year risk of BAVM hemorrhage in the subset of patients with intranidal aneurysms is considerably higher than the generally reported per-year risk rate of $2 \%-4 \%$ in the overall BAVM population. Hemorrhagic presentation, prenidal or intranidal aneurysms, and deep venous drainage were also found to be associated with increased risk of hemorrhage by other authors. ${ }^{13}$ Convincing data are lacking, however, regarding the correlation of other factors such as seizure presentation, size, age, sex, superficial venous drainage, and higher Spetzler-Martin grade with hemorrhage risk in long-term follow-up. ${ }^{13,45,76}$ Initial hemorrhagic presentation appears to be the strongest predictor for subsequent hemorrhage in untreated BAVM patients. ${ }^{71}$

\section{Classification}

Several authors have tried to categorize the aneurysms associated with BAVMs based on their hemodynamic or topographic relationship with the nidal component. $7,12,13,38,40,41,47,60,64$ These authors have in common the perception that an IA that is not flow related to the aneurysm (also called dysplastic or remote aneurysm ${ }^{41}$ ) should be seen and treated as an independent pathology, and the coexistence of those IAs and BAVMs in the same patient is most likely coincidental. However, there is significant divergence on the classification systems when describing aneurysms that are hemodynamically connected with the BAVM nidus. Venous aneurysms are in general excluded from these classifications.

Aneurysms associated with AVMs tend to be located on feeding arteries to the BAVM. Okamoto et al. were the first to statistically analyze this association in their literature review and description of an institutional experience in $1984 .^{58}$ In this pooled analysis of 78 case reports, including their own 5 cases, aneurysms were located on the respective feeding arteries more frequently than expected in the general aneurysm population. Their results strongly suggest that abnormal hemodynamic stresses on the feeding arteries to the BAVM play a significant role in the development of IAs on these arteries.
Our preferred classification system is the one described by Redekop et al., and it was used in our initial retrospective institutional review published in $1986^{7}$ (Fig. 1). It emphasizes the importance of hemodynamic factors on the formation and hemorrhage risks of aneurysms located on BAVM feeding vessels (Table 1). It takes into account several factors that appear to influence the formation of aneurysms in patients harboring BAVMs, such as increased regional blood flow, decreased resistance, and increased hemodynamic turbulence in BAVM feeders.

Several heterogeneous classification methods have been used in the literature to try to better characterize the association between BAVMs and IAs. The lack of a standardized nomenclature makes it difficult to determine the real incidence of IAs in patients with BAVMs. In the Cooperative Study, for example, $43 \%$ of the aneurysms were unrelated anatomically to the BAVM, $37 \%$ were located on a major BAVM feeder, and $20 \%$ were on the proximal segment of the feeding system. ${ }^{61}$ Our initial retrospective series included $18 \%$ of aneurysms that were remote from the BAVM. In contrast, Cunha et al. found an almost perfect correlation between BAVM and aneurysm location with only $1.6 \%$ of aneurysms arteries unrelated to the BAVM. ${ }^{12}$ Their numbers are in agreement with those of contemporary retrospective studies that analyzed the association between BAVMs and IAs, with Type I aneurysms representing less than 5\%.9,13,23,36,64,76

The presence of a flow-related or an intranidal aneurysm appears to be associated with an increased hemorrhage risk, both at initial presentation and recurrence. Redekop et al. identified 97 patients $(15.3 \%$ of their BAVM study population) with at least one aneurysm. ${ }^{64}$ The vast majority of patients had flow-related $(73.2 \%)$ or intranidal $(36.1 \%)$ aneurysms. Hemorrhagic presentation was twice as frequent in the subgroup with intranidal aneurysms as in the BAVM population without aneurysms (36\%) or the subgroup with flow-related or unrelated aneurysms (40\%). In cases in which a source of hemorrhage could be identified, flow-related aneurysms were the culprit in $41.4 \%$ of cases. The authors observed annual hemorrhage risks of 9.8\% (intranidal aneurysms) and 5.3\% (flow-related aneurysms) in the small subgroup of patients treated conservatively. During 57 patient-years of follow up, none of the patients with flow-related aneurysms experienced bleeding from the aneurysm itself. Regarding initial presentation of 39 patients with BAVM-associated aneurysms, Cunha et al. found that hemorrhage occurred in $62 \%$ of cases, with hemorrhage due to the aneurysm in $46 \%$ and to the BAVM in $33 \%$ of the cases. ${ }^{12}$

When specifically analyzing flow-related aneurysms, the evidence of association between those lesions and hemorrhage risks is strongest with distally located lesions. In our initial experience described in 1986 by the senior authors (H.H.B. and D.S.S.), 22 patients with an intracranial BAVM and at least one IA were retrospectively reviewed, and $41 \%$ of the patients presented with hemorrhage. ${ }^{7}$ A striking $50 \%$ of these patients harbored multiple aneurysms. Of all the aneurysms detected, $82 \%$ were located in hemodynamic association with the malformation (50\% proximally along the feeding vessel, 32\% on atypical distal points). Seven of the 9 patients who pre- 

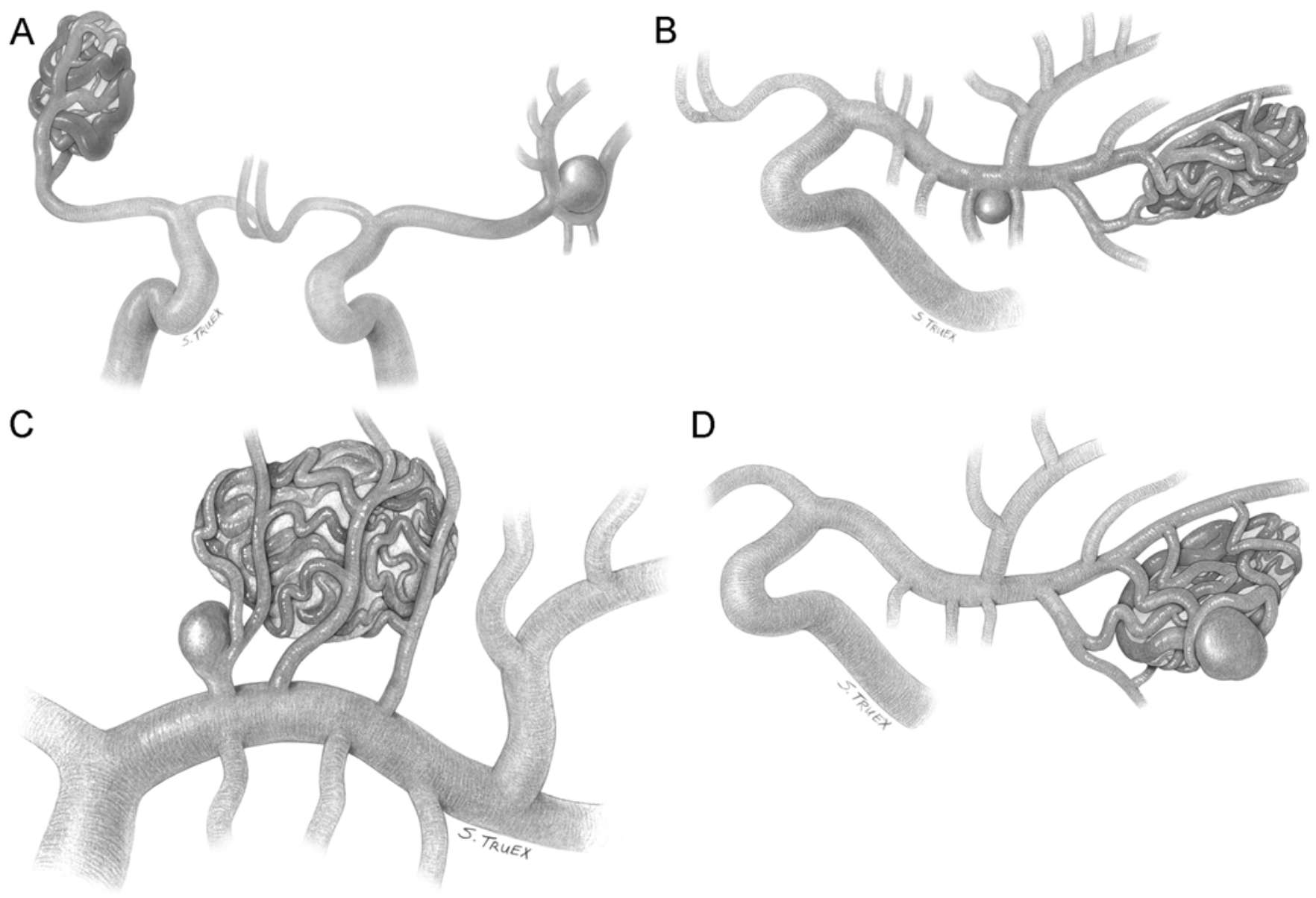

Fig. 1. Classification of IAs associated with AVMs, as described by Redekop et al. A: Type I (unrelated). B: Type lla (proximal flow related). C: Type Ilb (distal flow related). D: Type III (intranidal). Refer to Table 1 for full description. Copyright Suzanne R. Truex. Published with permission.

sented with hemorrhage had bleeding from the aneurysm, located in one of the atypical distal sites on major feeding vessels. None of the aneurysms at sites remote from the BAVM ever bled. It is our opinion that the natural history of Type I aneurysms is similar to that of general IAs; they have a coincidental rather than a consequential relationship with BAVMs. Perata et al. reported their experience with 4 distal flow-related aneurysms (which they called feeding artery pedicle aneurysms) and concluded that these lesions represented a significant source of intracerebral hemorrhage and risk for rehemorrhage. ${ }^{60}$ They argued in favor of prompt and aggressive management of the aneurysm itself with embolization in cases when BAVM resection must be delayed or in cases of stereotactic radiosurgery.$^{60}$ More recently, other authors have found distal but not proximal flow-related aneurysms to be associated with ICH presentation. ${ }^{36}$

The association of intranidal aneurysms with hemorrhagic presentation appears to be more conclusive. In their analysis of 125 patients with angiographically confirmed BAVMs, Marks et al. identified 15 patients with intranidal aneurysms; all of them had a history of bleeding..$^{48}$ Based on those findings, and on their success with adjuvant endovascular embolization of intranidal aneu- rysms in patients undergoing stereotactic radiosurgery (SRS), the authors suggested a potential benefit of partial BAVM embolization (targeted to the intranidal aneurysm and its feeder) in reducing the risks of bleeding during the latency period after radiosurgical treatment. Other authors have correlated the number of associated intranidal aneurysms with larger, high-flow BAVMs.$^{51}$ In this study, the presence of proximal or intranidal aneurysms did not translate into higher initial bleeding rates, but patients with intranidal aneurysms exhibited higher rate of rebleeding before treatment that remained significant after multivariate analysis. No aneurysmal bleeding was noticed after targeted embolization of proximal or intranidal aneurysms.

Controversy exists regarding the etiology of both distal flow-related and intranidal aneurysms. Some authors have raised the question of whether those lesions, located near the BAVM nidus and identified on angiography following a hemorrhage, represent true aneurysms or pseudoaneurysms that developed from the rupture of small, thin-walled vessels..$^{20,47,48,64}$ That differentiation has obviously important clinical and risk stratification implications. If one considers the majority of these lesions as pseudoaneurysms, resultant from previous hemorrhages, 


\section{Management of AVM-associated aneurysms}

\section{TABLE 1: Classification of intracranial aneurysms associated with arteriovenous malformations*}

\begin{tabular}{|c|c|}
\hline Lesion Type & Description \\
\hline Type I & unrelated: located on a vessel w/ no direct supply or hemodynamic correlation w/ the BAVM itself \\
\hline Type II & flow-related \\
\hline Ila & $\begin{array}{l}\text { proximal: located in a main intracranial vessel, up to its primary bifurcation (e.g., VA, BA, circle of Willis including PCoA \& ACoA, } \\
\text { supraclinoid ICA, MCA }\left(M_{1}\right), A C A\left(A_{1}\right)\end{array}$ \\
\hline Ilb & distal: located at midpoint or distally on a direct BAVM feeder, or distally to the Type lla vessels \\
\hline Type III & intranidal: located w/in the BAVM nidus itself, fills early on angiographic arterial phase, before substantial venous filling has occurred \\
\hline
\end{tabular}

\footnotetext{
* Modified with permission from Redekop G, TerBrugge K, Montanera W, et al.: Arterial aneurysms associated with cerebral arteriovenous malforma-
} tions: classification, incidence, and risk of hemorrhage. J Neurosurg 89 (4):539-546, 1998.

then it would be inappropriate to extrapolate a high risk of bleeding to intranidal aneurysms found on BAVMs that have not bled. Histological evidence from surgical specimens ${ }^{48}$ and clinical reports of patients with angiography-detected intranidal aneurysms in the absence of clinical or radiographic evidence of hemorrhage ${ }^{64}$ argue to the contrary. Those facts, in association with the angiographic similarities of distal flow-related and intranidal lesions to aneurysms located elsewhere, represent compelling evidence in favor of the true aneurysm etiology theory.

\section{Treatment}

The physician must be able to tell the antecedents, know the present, and foretell the future-must mediate these things, and have two special objects in view with regard to disease, namely, to do good or to do no harm.

\section{OF THE EPIDEMICS (400 B.C.), HipPOCRATES}

One can arguably affirm that in no other cerebrovascular pathology is this Hippocratic quote as pertinent as in the management of AVMs. The ultimate goals of the treatment of a BAVMs are to prevent hemorrhage, avoid a stepwise neurological deterioration, and eliminate the mortality risk associated with recurrent hemorrhagic events. However, the treatment of BAVMs is only justifiable if the risks associated with an intervention are lower or equivalent to the long-term risks of disability or mortality caused by the lesion itself. Although some question the need for resection of a BAVM, it is fair to say that none question the need to resect them safely.

Partial treatment (especially targeted endovascular embolization or SRS) of a BAVM nidus does not appear to positively influence the natural history of the disease, and in some cases it can actually be detrimental. ${ }^{11,27}$ The goal of operative intervention in all BAVMs should be the complete removal of the malformation, as documented by postoperative angiography. Only total BAVM excision or obliteration can completely avoid the risk of subsequent hemorrhage or progression of ischemic neurological deficits. ${ }^{6}$ In the specific case of BAVMs associated with IAs, several factors should be taken into consideration before recommending treatment of one or both of those lesions. There is no consensus in the literature about the best management strategies, and the available studies repre- sent anecdotal or institution-specific case series with treatment algorithms that cannot be reliably extrapolated to the general population. The rarity of the association of those diseases, the tendency for those complex cases to be concentrated in tertiary cerebrovascular centers (and the resultant selection and referral bias), the lack of uniformity of the classification and reporting systems, and the pertinent ethical aspects that prevent true randomization analysis of treatment paradigms are just a few examples of the difficulties faced by the treating neurosurgeon when dealing with patients harboring BAVMs with associated aneurysms.

To assess the outcome of the management of BAVMs, and to facilitate comparison between different institutional series, a pretreatment grading scale is necessary. It should include reliable prognostic factors and be inclusive, reproducible, and consistent. The most widely accepted and regularly used system is the Spetzler-Martin grading scale, based on BAVM nidus size, pattern of venous drainage, and eloquence of adjacent parenchyma. ${ }^{68}$ It is relatively simple and a reliable discriminator of relative surgical risks. Nevertheless, it has been frequently criticized for the lack of weighting and independence of variables, the need for further BAVM subclassification, and the intra- and interobserver error and biasing from patient exclusion because of perceived preoperative risks. ${ }^{55}$ In 2011, this grading system was simplified by Spetzler and Ponce into a 3 -tiered classification. ${ }^{69}$

The main point of controversy for the original Spetzler-Martin grading scale involves the management of Grade III BAVMs. This group is the most heterogeneous, with 4 different combinations of size, venous drainage, and eloquence. ${ }^{43}$ Several modifications of the original Spetzler-Martin BAVM grading system have been described in an attempt to overcome those limitations. ${ }^{15,43,44,69}$ The description of these scales and an indepth analysis of their clinical implications have been extensively reported in the neurosurgical literature and are beyond the scope of the present study. It is important to emphasize, though, that none of the major grading systems evaluated the presence of associated IAs as a variable in the treatment decision-making process for the different types of BAVMs.

\section{Microsurgery}

The presence of a BAVM-associated aneurysm 


\section{B. C. Flores et al.}

should not significantly change the microsurgical techniques for the resection of the nidal component. Adequate exposure is of paramount importance. The surgeon must have access to the malformation, its feeding arteries, and its draining veins while applying minimal brain retraction. ${ }^{16}$ If both BAVM and IA are targeted in the same operation, head positioning and craniotomy should be modified to include adequate proximal control before aneurysm microdissection. If the decision was made to treat the IA and not the BAVM, the craniotomy should be dictated by the aneurysm. Patients who present with hemorrhage of unknown source probably benefit from a wider exposure through which both lesions could be addressed safely, a precaution that can avoid unpleasant and potentially disastrous intraoperative surprises. Early clip ligation of all possible feeding arteries at the BAVM margin is a key first step in resection and should be followed by meticulous microsurgical dissection of the entire BAVM periphery, sparing all possible venous drainage. ${ }^{6}$ Prompt differentiation of direct BAVM feeders from en passage vessels should be completed early in the microdissection process to avoid ischemia of important brain tissue located distally to the nidus; only the small BAVM-feeding side branches should be taken with preservation of the main branch. Distal flow-related aneurysms are rarely associated with en passage vessels.

Small aneurysm clips are used on all BAVM direct feeders larger than a few millimeters in luminal diameter. This clipping technique is also an excellent strategy for fragile, enlarged periependymal arterioles that frequently prove refractory to bipolar cauterization. Even with a tedious but systematic circumferential nidal dissection, the microsurgical resection technique confines the surgeon's dissection to the gliotic margins of the BAVM. Working in the boundary between abnormal gliotic brain and functional parenchyma, using bipolar cautery, microscissors, aneurysm clips, and having an ever-present suction tip exerting light retraction will minimize the chance of iatrogenic injury to normal surrounding brain tissue and important adjacent vasculature. ${ }^{6,56}$ This technique does not, unfortunately, exclude the risk of inadvertent isolation of small parts of malformation, a complication that may result in serious intraoperative or postoperative hemorrhage and potentially devastating neurological consequences.

Excluding incomplete BAVM nidal resection, two other hypotheses have been posited to explain the causes of intra- or postoperative brain hemorrhage and refractory edema: normal perfusion pressure breakthrough (NPPB) and occlusive hyperemia. The NPPB theory, initially proposed by Spetzler et al. in $1978,{ }^{70}$ suggested that postoperative hemorrhage and edema are caused by a failure in autoregulation in the ischemic brain around the BAVM. The chronic hypoperfusion would cause maximal chronic vasodilation and inability of these vessels to react with vasoconstriction to the resumption of normal perfusion pressure after the BAVM resection. The key to prevention of malignant postoperative hemorrhage and edema would be staged reduction of the blood supply to the malformation, through a staged surgical ligation or endovascular embolization of the feeders. ${ }^{5,14,57,70}$ The NPPB theory is well described but lacks scientific validation. It is not ap- plicable to most cases of malignant postoperative hemorrhage and edema. Intraoperative studies have demonstrated maintained autoregulation in the region surrounding a BAVM both before and immediately after its resection, even in cases subsequently complicated by edema and hemorrhage. ${ }^{57}$

The occlusive hyperemia postulates that malignant postoperative hemorrhage and edema are caused by either arterial stagnation or venous outflow obstruction, both of which are in turn direct result of BAVM resection. It is supported by the observation that long feeding arteries correlate with a greater risk of postoperative deterioration than do short vessels of similar diameter and flow. If this theory is true, the indications for staged resection would be limited to those cases necessitated by technical factors, and hypotensive therapy in the management of postoperative edema may prove deleterious. ${ }^{2,57}$ To date, there has been no studies correlating either of those two theories-NPPB or occlusive hyperemia-with the coexistence of BAVM-associated aneurysms.

Patients presenting with hemorrhage secondary to BAVM rupture are rarely managed surgically during the acute phase. Delaying surgery allows the patient to recover from the initial hemorrhage, facilitates hematoma organization or resolution, and allows for the evolution of dissection planes between the hematoma and the surrounding parenchyma. ${ }^{21}$ Occasionally (and most often seen with infratentorial lesions), the BAVM presentation is of a comatose patient with a large cerebral or cerebellar hematoma that requires emergency evacuation. In that situation, the goal is to evacuate the hematoma and reduce the acute mass effect or hydrocephalus, leaving the BAVM intact. Whenever feasible, however, definitive BAVM resection should be deferred for 4-6 weeks. ${ }^{21}$ This allows sufficient time for perilesional edema to diminish and the hematoma to liquefy. More so, associated flowrelated or intranidal IAs might initially be obscured by intraparenchymal hemorrhage on the first angiogram. On rare occasions, an operation initially targeting hematoma evacuation might ultimately require complete BAVM resection during the same procedure if one encounters uncontrollable intraoperative hemorrhage.

Immediate postoperative angiography is performed in all patients who have undergone BAVMs resection while they are still under general anesthesia to verify complete resection. The presence of any residual malformation is an indication to return the patient immediately to the operating room to complete the surgical procedure. This routine has been instrumental in minimizing the incidence of serious postoperative complications.

Hemorrhage from a BAVM can be complicated by intraventricular hemorrhage (IVH) in $16 \%$ of the cases. ${ }^{63}$ Occasionally, patients present with an isolated IVH without evidence of intraparenchymal hematoma (Fig. 2). In these cases, the presence of a Type IIb aneurysm located at the intraventricular segment of the choroidal artery should be excluded. These patients usually present in a comatose state as a result of the IVH and obstructive hydrocephalus, being initially managed by placement of an external ventricular drain. Whenever feasible, the aneurysm can be treated with endovascular or microsurgical 


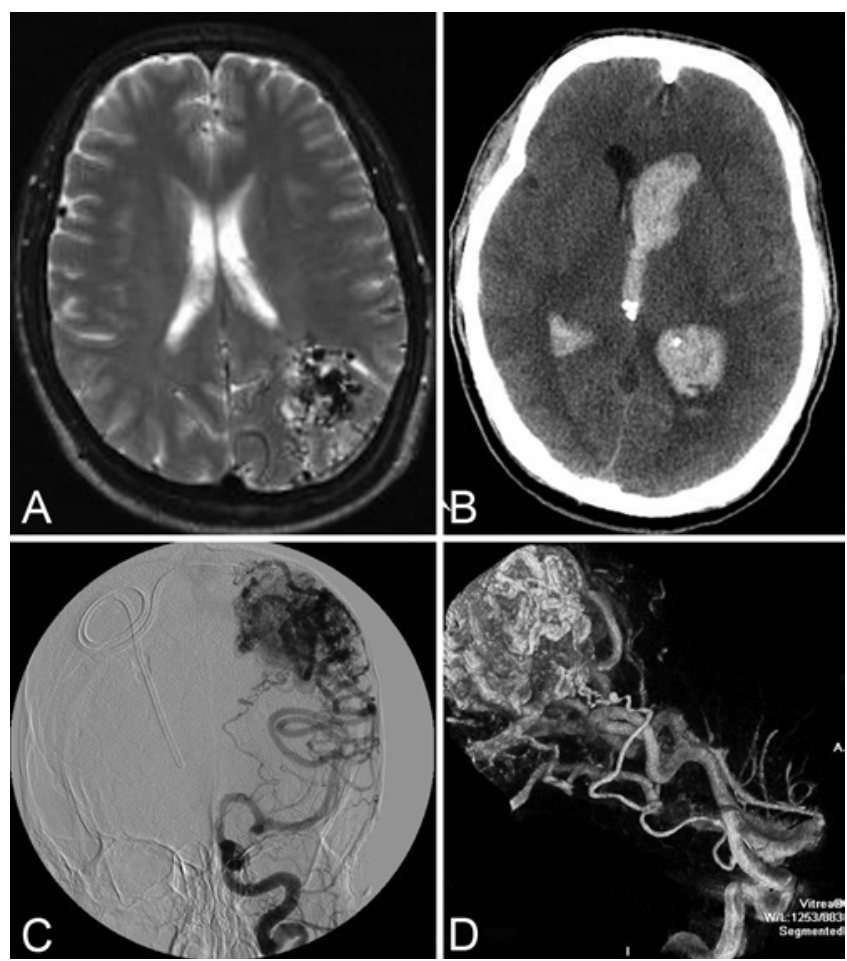

FIG. 2. Intraventricular Type IIb aneurysm presenting with isolated IVH in a 50-year-old man. A: An unruptured left parietooccipital BAVM was diagnosed on workup for seizures. B: He presented to the hospital several years later with worsening headaches, nausea, and vomiting and admission CT showed an extensive IVH with no intraparenchymal hemorrhage. $\quad \mathbf{C}$ and $\mathbf{D}$ : Catheter angiography revealed a 3-mm Type Ilb aneurysm arising from the distal left anterior choroidal artery, thought to be the source of hemorrhage. Other aneurysms were also identified at the anterior communicating artery, the left anterior temporal artery, and the superior division of the left middle cerebral artery.

techniques. After the aneurysm is secured, intrathecal tissue plasminogen activator is administered to aid with IVH resolution and presumably reduce the probability of shunt-dependent hydrocephalus. Some case reports in the literature describe the safe use of tissue plasminogen activator in patients with IVH and an unsecured BAVM or aneurysm..$^{39,49}$ We do not recommend the use of intraventricular thrombolytics in patients with unsecured vascular lesions because of the potential catastrophic outcome. ${ }^{66}$

Independent of the grading system used, the surgical outcome for BAVM resection is directly related to the angioarchitecture and location of the BAVM. We have previously reported our early experience with the surgical management of intracranial AVMs with associated IAs.? In that retrospective review of 22 patients, $69 \%$ had good outcome, and the mortality rate was $26 \%$. It is difficult to compare those numbers to the contemporary treatment of patients with coexisting BAVMs and aneurysms, since the majority of the published large case series lack specific information about surgical morbidity and mortality. An extrapolation from the general BAVM surgical data appears to be a more coherent approach. In their initial report from 1986, Spetzler and Martin evaluated the predictive value of their grading scale in a cohort of 100 consecutive BAVMs and found an overall $10 \%$ rate of minor and $4 \%$ rate of major deficits. There were no deaths. ${ }^{68}$ A clear positive correlation between the grading scale score and outcome was noticed and has been corroborated by other authors, as described in a pooled analysis of surgical outcomes from 7 large surgical series. ${ }^{69}$ The combined rate of negative outcome varied from $4 \%$ and $10 \%$ (Grades I and II BAVMs, respectively) to $31 \%$ and $37 \%$ (Grades IV and V, respectively). Lawton ${ }^{43}$ stratified the heterogeneous group of Grade III BAVMs into 3 additional subcategories with a low (2.9\%), intermediate $(7.1 \%)$, and high $(14.8 \%)$ risk of postsurgical death or new deficit. Heros et al. described the marked tendency for postoperative neurological deficits to improve with time, so that whereas the immediate postoperative rate of serious morbidity was $24.2 \%$, only $7.8 \%$ of the patients were found to have serious morbidity at follow-up. Their low BAVM-related mortality rate of $1.3 \%$ is even more significant when one realizes that $40 \%$ of the patients harbored Grade IV and V BAVMs. ${ }^{26}$

\section{Endovascular Treatment}

Liquid embolic agents (e.g., Onyx and $N$-butyl cyanoacrylate) and flow-directed and flow-assisted microcatheters represent some of the most recent advancements in endovascular tools that have greatly expanded the treatment options for BAVMs. Detachable coils may be used for embolization of particularly high-flow arteries, direct aneurysm treatment, or selective flow reduction for a safer use of liquid embolic agents without high risk of shunting through the venous system. The main advantage of the endovascular management of BAVMs is as an adjuvant to microsurgical and radiosurgical techniques, a multimodality approach that has rapidly become standard of care for some BAVM subtypes. Frequent goals of preoperative neurointerventional treatment include decrease in overall arterial supply, superselective embolization of deep arterial feeders, and nidal reduction to facilitate BAVM resection. Preoperative embolization has proved to be beneficial and often indispensable for gradually reducing BAVM flow before surgery and for limiting intraoperative blood loss and operating time. Embolization before SRS may be applied to reduce BAVM target size and eliminate potential high-risk features, such as flowrelated or intranidal aneurysms. ${ }^{11,33,34,46,62}$ However, the effectiveness of this approach is still debatable. Preoperative BAVM embolization remains the main indication in the majority of neurosurgical centers. Even in the cases of ruptured BAVMs, recent reports have suggested that early embolization may be safe, particularly if the goal of embolization is to eliminate high-risk features that may increase the rehemorrhage rates. ${ }^{73}$

Curative BAVM embolization often requires aggressive nidal embolization and may be associated with prohibitive complication rates, largely related to unintended early occlusion of draining veins. BAVMs that are most likely to be cured using endovascular treatment have a small nidus and limited number of feeders (particularly those of Spetzler-Martin Grades I-III), characteristics that also make those lesions perfect microsurgical candidates, with associated low morbidity and mortality rates. ${ }^{11}$ Historically, BAVM cure rates with endovascular alone have 


\section{B. C. Flores et al.}

been low, with pre-Onyx era data showing angiographically confirmed occlusion rates of $5 \%-22 \% .{ }^{11,24,27,37,38,78}$ Higher cure rates were restricted to lesions with a volume less than $4 \mathrm{ml}^{18,48,82}$ Over the last 5 years, a few authors have reported their experience with Onyx embolization, demonstrating endovascular cure rates as high as $28 \%$ $55 \% .^{11,27}$ Using a double-arterial catheterization technique, Abud et al. achieved a BAVM angiographic occlusion rate of $94.1 \%$, with an overall clinical complication rate of $11.7 \%$ of and no deaths. ${ }^{1}$ Despite those promising results, current endovascular neurointerventional techniques for curative BAVM embolization carry with them high periprocedural risks and failure rates, and should be reserved for small BAVMs located in areas where resection would result in particularly high morbidity.

Except for very few occasions, the partial treatment of a BAVM nidus appears to increase the risk of future hemorrhage and is not indicated..$^{11,27,52}$ One of the few areas where there is debatable benefit is in the management of aneurysms associated with BAVMs. Probably the most frequently cited article that supports the benefits of partial targeted embolization was written by Redekop et al. ${ }^{64}$ In this study, the authors retrospectively reviewed their institutional experience over a decade and identified 35 intranidal and 71 flow-related aneurysms in a cohort of 632 patients with BAVMs. Distal flow-related aneurysms were found to have a high probability of regression associated with subtotal or curative BAVM treatment, with $80 \%$ completely regressing after BAVM obliteration and $67 \%$ disappearing after reduction of the BAVM nidus by more than 50\%. ${ }^{17,64}$ Proximal aneurysms regressed infrequently even after BAVM cure (17.4\% decreased in size and $4.3 \%$ disappeared). None of the aneurysms decreased in size or disappeared in patients in whom the size of the BAVM nidus was reduced by less than $50 \%$; during the follow-up period, 2 patients experienced SAH secondary to proximal flow-related aneurysms rupture. It is important to point out that the authors did not clearly specify the treatment modalities applied in each of the treated patients in the overall population, their procedural complication rates, or outcomes. Other authors have reported similarly successful experiences. ${ }^{12,46,51,53,62}$

Partial or targeted BAVM embolization in an attempt to reduce hemorrhage risks has minimal to no application. It is not applied as a single treatment modality in the management of unruptured BAVMs even in the presence of associated flow-related or intranidal aneurysms. As evidenced by historical data and the recent ARUBA report, this approach can be associated with higher mortality and stroke rates when compared with medical or conservative management alone. Targeted embolization is reserved only for patients with hemorrhage at presentation, when an associated distal flow-related aneurysm is thought to be the bleeding source and can be safely occluded using endovascular techniques, or when a ruptured BAVM nidus has certain angioarchitectural features that would theoretically increase the chances of early rehemorrhage (such as a high-flow fistulous component, significant venous outflow obstruction, or a large intranidal aneurysm considered to be the source of initial BAVM bleed).

Some authors favor the so-called palliative emboliza- tion for symptomatic, large, high-flow BAVMs that are thought to cause symptoms through steal phenomenon, relative hypoperfusion of the surrounding parenchyma, or compressive cranial nerve neuropathies. Most of the data on this topic come from small case reports and lack adequate evidence support. At our institution, this controversial practice is only applied for Spetzler-Martin Grades IV or IV AVMs in patients who are not candidates for resection or SRS and whose clinical symptoms are clearly associated with specific BAVM features that can be safely addressed through endovascular neurointerventional techniques (e.g., chronic headaches and large external carotid artery feeding branches, progressive visual loss due to recruitment of ophthalmic artery feeders or significant ophthalmic vein draining pattern, trigeminal neuralgia, etc.).

Despite this multitude of applications, the treating neurosurgeon should keep in mind the inherent risks associated with endovascular embolization of BAVMs. Our institution has previously published our 11-year results for preoperative embolization of these lesions. ${ }^{75}$ In that series that involved 339 procedures performed in 201 patients, preoperative embolization was associated with a $1.2 \%$ mortality rate and a $6.5 \%$ permanent neurological deficit rate per procedure, or $2 \%$ and $9 \%$ of the patients, respectively. Univariate statistical analysis did not show significant an association of factors such as patient age, sex, BAVM location and type of embolic agents with a poor outcome.

Those numbers are not different from those reported in 2009 by Hauck et al., who analyzed their experience with Onyx for the preoperative embolization of cerebral BAVMs. ${ }^{24}$ A new permanent neurological deficit occurred in 5 patients $(6.1 \%$ per procedure or $12.2 \%$ per patient), and there were no deaths in a cohort of 41 patients; similar numbers have been cited by other contemporary case series. ${ }^{24,27,52}$

A recent meta-analysis of 137 observational studies showed that complications leading to permanent neurological deficits or death occurred in a median of $7.4 \%$ (range $0 \%-40 \%$ ) of the patients after microsurgery, $5.1 \%$ (range $0 \%-21 \%$ ) after SRS, and 6.6\% (range 0\%-28\%) after embolization. Successful BAVM obliteration was achieved in $96 \%$ (range $0 \%-100 \%$ ) of patients after microsurgery, $38 \%$ (range $0 \%-75 \%$ ) after SRS, and $13 \%$ (range 0\%-94\%) after embolization. ${ }^{78}$ Published results from the Japanese Registry of Neuroendovascular Therapy on endovascular embolization of cerebral BAVMs showed a $9.2 \%$ incidence of complications and $0.3 \%$ mortality rate. In univariate analysis, deep venous drainage, concurrent aneurysm, and embolization of 4 or more pedicles per session were significantly associated with treatment-related complications. ${ }^{37}$ In general, though, the risk profile for the endovascular treatment of BAVMs associated with aneurysms does not appear to be significantly different from the overall ones described above. ${ }^{37,46,62}$

\section{Radiosurgery}

Concurrent to the modern endovascular neurointerventional techniques, the emergence of stereotactic radiosurgery has revolutionized the treatment of BAVMs. 
Together, these two treatment modalities have significantly expanded the armamentarium of the cerebrovascular neurosurgeon, and made possible to safely treat complex lesions for what surgical resection was not applicable.

Characteristics and postsurgical complications of BAVMs differ markedly in patients treated by SRS versus microsurgery. Lesions most effectively treated with SRS have volumes $<10 \mathrm{~cm}^{3}$ or maximum diameter $<3 \mathrm{~cm}$. A small AVM size, single draining vein, low SpetzlerMartin grade, high margin or maximum dose, male sex, and previous hemorrhage are all factors that are believed to be predictors of obliteration after BAVM radiosurgery. ${ }^{33,34,72}$ Obliteration rates following SRS range from $54 \%$ to $92 \%$, when considering catheter angiography the reference diagnostic study. Controversy still exists about the degree of protection provided by radiosurgery against hemorrhage during the latency period (generally 1-3 years). Despite the wide range of numbers reported in the literature $(1.6 \%-9 \%$ total), it is generally accepted that the risk of hemorrhage during the latency period is not significantly different from the risk prior to treatment. ${ }^{72}$

Preradiosurgical embolization of a BAVM has been used frequently, but the strategy has mixed results and debatable utility. The goal is usually to eliminate BAVM features that would otherwise make it less likely to respond to SRS. Some authors have reported obliteration rates of $60 \%-81 \%$ with this multimodality treatment, with most studies completed in the pre-Onyx era. Others have reported consistently decreased obliteration rates associated with preradiosurgical embolization. ${ }^{11,27}$

The association between BAVMs and IAs has been well described in the radiosurgical literature. In a retrospective analysis of almost 2 decades of institutional data, Kano et al. found the incidence of BAVMs with coexisting aneurysms to be $9.7 \%$. The annual bleeding rates in patients with and without a coexisting aneurysm were $11 \%$ and $1.5 \%$, respectively. The rate of AVM bleeding during a 5-year period after SRS was 10 times higher in the presence of an aneurysm (28\% vs $2.6 \%$ ). The morbidity rate after SRS was $19 \%$ in patients with associated IAs, compared with $1 \%$ in those without aneurysms. ${ }^{34}$ In a separate study, the same authors concluded that the presence of a patent aneurysm was significantly associated with an increased risk of rehemorrhage after SRS, when compared with patients with clipped or embolized aneurysms. The patients with coexisting aneurysms had a 5 times increased risk of hemorrhage than patients without an aneurysm or those who had undergone microsurgical or endovascular obliteration of their aneurysms. ${ }^{33}$ Their data supports the concept that aggressive microsurgical or endovascular management of BAVM-associated aneurysms should be considered to reduce the risk of a hemorrhage during the latency period after SRS.

Posttreatment morbidity is directly associated with BAVM location and the volume of tissue receiving more than 12 Gy. ${ }^{73}$ Some of the common side effects include headaches, seizures, and radiation-induced changes in the surrounding brain structures (edema, necrosis, or cyst formation). Permanent deficits can be seen in $0.4 \%-20.6 \%$ of treated patients. A detailed discussion about the role of $\mathrm{SRS}$ in the management of different types of BAVMs is beyond the scope of this study. The most interested reader should refer to recent detailed institutional series, published in 2012. ${ }^{28-32,34}$

\section{Institutional Experience}

Our early experience treating BAVMs associated with IAs has been previously published. 'Between 1977 and 1986, 22 patients with this combination of lesions were evaluated at our institution. Nine patients (41\%) presented after intracranial hemorrhage. Among the patients suffering intracranial hemorrhage, $78 \%$ had bled from an aneurysm and 22\% from their BAVM. In all 7 of the patients who suffered aneurysmal hemorrhage, the bleeding was from atypical distal aneurysms on major feeding vessels. Together, these findings have led us to believe that the safest approach to this combination of lesions is to treat the aneurysm before microsurgical resection of the associated BAVM.

We have recently updated our original case series to include the data collected over the last 25 years (unpublished data). A retrospective review was undertaken to identify all patients with BAVMs and IAs admitted to University of Texas Southwestern Medical Center from 1990 until 2014. Patients with isolated intranidal aneurysms, those who were asymptomatic, and those who did not undergo treatment intervention during the long-term follow-up were excluded from the analysis.

Eighty-two patients met the study inclusion criteria. Their mean age at presentation was 48 years. The majority were female $(67.1 \%)$ and presented after hemorrhage (61\%). Supratentorial BAVMs (69.5\%) were more frequent than infratentorial lesions $(30.5 \%)$. When hemorrhage occurred, an IA was thought to be the source of hemorrhage in $46 \%$ of the patients, a BAVM in $46 \%$ of patients, and the source was undetermined in $8 \%$. Twenty-four patients (29.3\% of the study population) had multiple IAs, with the majority of the identified aneurysms being Type IIa $(54.9 \%)$ or Type IIb (36.6\%). Treatment was directed toward obliteration of both BAVM and IA in the majority of the cases $(68.3 \%)$, but not necessarily during the same admission; in all the cases in which a staged procedure was planned, the IA was treated first. The overall perioperative morbidity rate for all treatment modalities was $23.2 \%$. There were 2 perioperative deaths $(2.4 \%)$ resulting from devastating hemorrhage and poor neurological function. Both patients presented with a ruptured infratentorial AVM, extensive intraventricular and intraparenchymal hemorrhages, and their conditions failed to improve despite surgical and endovascular treatments.

\section{Proposed Management Algorithm}

Our current management of IAs associated with AVMs is summarized in Figs. 3 and 4. It is important to emphasize that, to the best of our knowledge, the current literature recommendations for the treatment of those coexisting vascular lesions are largely based on case series or expert opinions and, as such, represent Class III evidence. The present manuscript does not deviate from this 

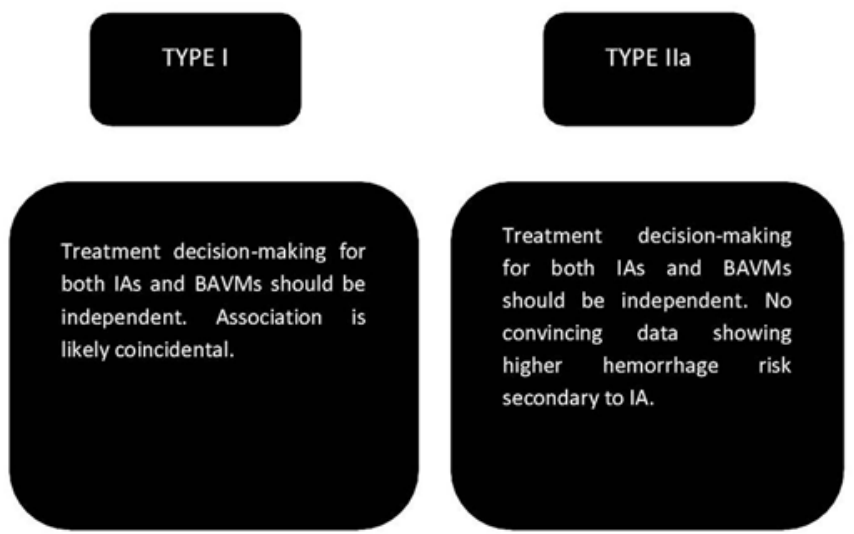
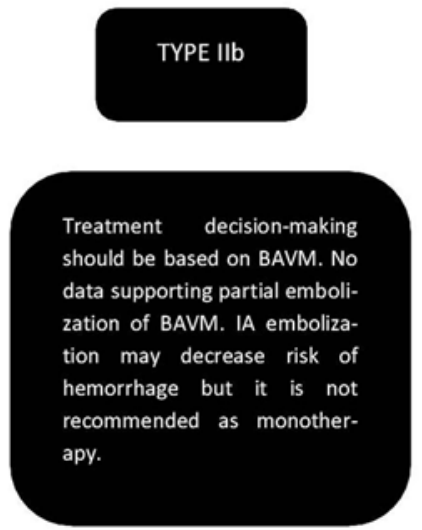
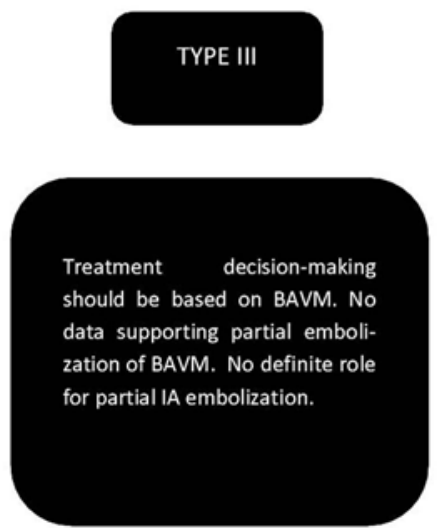

FIG. 3. Proposed management algorithm for IAs associated with BAVMs that present without hemorrhage.

theme. The proposed management strategies described below are based on the experience accumulated by the senior authors (H.H.B. and D.S.S.) and are still applied at our institution.

For a thorough understanding and judicious decision making, when faced with IAs associated with BAVMs, a few questions need to be answered by the treating neurosurgeon:

1) What is the mode of presentation (hemorrhage, seizures, headaches, incidental, etc.)?

2) What is the symptomatic lesion? In cases of hemorrhage at presentation, which one of the lesions (BAVM or IA) bled?

3) What is the angioarchitectural relationship between the BAVM and the IA?

4) Is the IA safely treatable? What are the possible treatment modalities and risks?

5) Is the BAVM safely treatable? What are the possible treatment modalities and risks?

6) Is it possible to safely treat both BAVM and IA with a single procedure?

Probably the most controversial group is the one formed by patients who present with no history of current or remote hemorrhage. The current ARUBA data corroborate earlier reports that described a low rate of spontaneous BAVM rupture. ${ }^{22,25,54}$ More importantly, its preliminary results showed unexpectedly higher risk of death or stroke in the interventional therapy group when compared with the medical management alone. ${ }^{54}$

When a patient presents with an unruptured BAVM associated with Type I or IIa aneurysms, the management should be based on the aneurysm itself (Fig. 3); the association between BAVM and IA in those patients is likely coincidental. In contrast, patients with Type IIb and III aneurysms should have the treatment decision based on the AVM itself. We do not advocate undertaking partial BAVM embolization or selective embolization of an unruptured intranidal aneurysm as a sole treatment modality. Surgical treatment directed toward the aneurysm only is almost certainly not indicated, and endovascular treatment carries a much higher risk than is generally understood. If both lesions are surgically accessible with reasonably low potential morbidity, they should be treated simultaneously. In the Type IIb aneurysms, if the decision is made to proceed with radiosurgical treatment of the BAVM, then the IA should be secured (either with surgical or endovascular techniques) prior to SRS.

The management of a patient presenting with hemorrhage should be aimed at the symptomatic lesion. It can be frequently difficult to determine the source of hemorrhage, particularly with intranidal aneurysms. In the cases in which the patients present with isolated SAH, almost always the aneurysm is the culprit and treatment should be directed at it. If there are several aneurysms, all should be treated if possible. Once the aneurysm is determined to be the bleeding source, it should be secured first, independent of its association with the BAVM. That is true for all aneurysm types except those that are Type III; there is currently weak data to support targeted embolization of an intranidal aneurysm. Only in exceptional cases of large or unusual intranidal aneurysms, or in cases of an early rebleed, should the nidal lesion alone be targeted. Otherwise, targeted embolization of a Type III aneurysm should be used as part of a combined multimodality approach including microsurgery or SRS.

In patients who present with intracerebral hemorrhage (with or without IVH), the BAVM or BAVM-nidal aneurysm is the culprit. The risk of early rehemorrhage is relatively low. Once the BAVM has been determined to 


\section{Management of AVM-associated aneurysms}

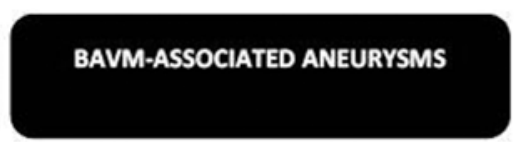

HEMORRHAGE
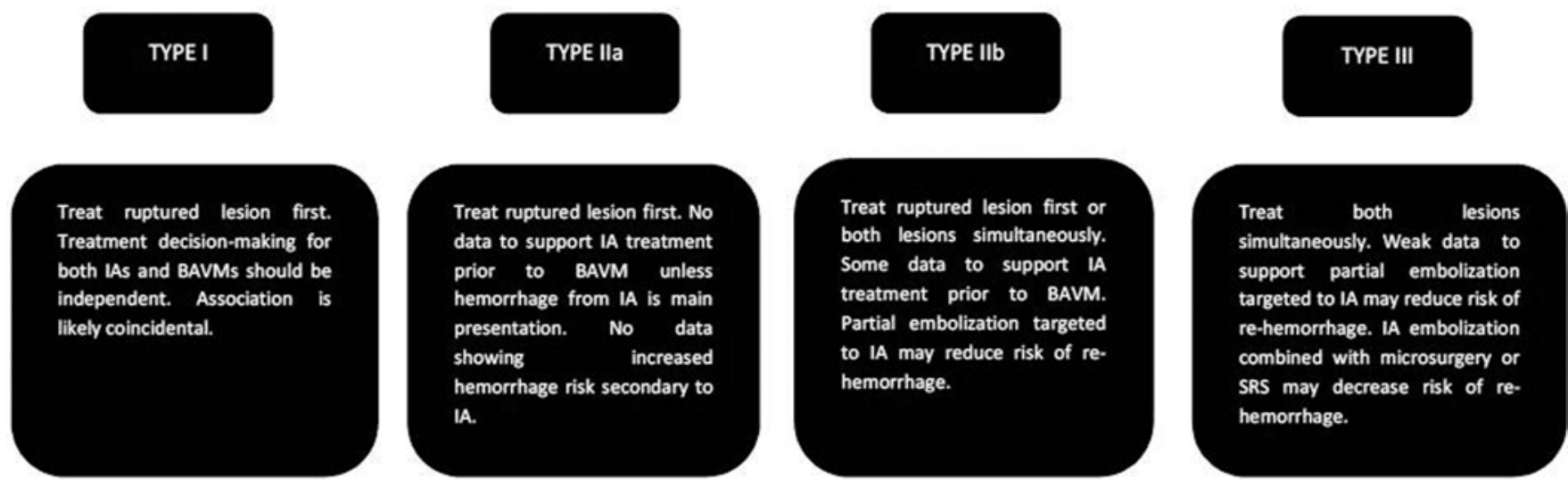

FIG. 4. Proposed management algorithm for IAs associated with BAVMs that present with hemorrhage.

be the source of hemorrhage and there are no indications for surgical evacuation of an intraparenchymal hemorrhage, the patient should be medically managed during the acute phase and a repeat catheter angiography obtained in 4-6 weeks, after the hematoma is reabsorbed. Subsequent treatment should be well planned, judicious and aimed at obliteration of both the BAVM and IA, if possible. If the treating neurosurgeon cannot reliably determine the bleeding source, both lesions should be treated simultaneously, if possible. Otherwise, the treatment should be directed toward the aneurysm first because of its higher rerupture risk and thus increased morbidity and mortality rates.

\section{Conclusions}

Intracranial aneurysms associated with AVMs are challenging, fascinating lesions treated by the cerebrovascular neurosurgeon. Their coexistence is well documented in the literature and cannot be solely explained by random association. Patients with both BAVM and IA tend to have higher hemorrhage rates at presentation and higher rehemorrhage rates, thus having a more aggressive course and natural history. The risk of intracranial hemorrhage in patients with a coexisting BAVM and IA is approximately $7 \%$ per year, a rate significantly higher than rates seen in patients harboring only one of those lesions.

When stratified by their location and hemodynamic relationship to the BAVM, it appears that Type IIb and III aneurysms have the strongest association with increased hemorrhage and rehemorrhage rates. Type I aneurysms have the same natural history and overall hemorrhage risks of the general IA population, and their coexistence with a BAVM is most likely coincidental. There are conflicting data about the degree of association between
Type IIa aneurysms and BAVMs, as well as the interplay of those two vascular lesions in the overall patient hemorrhage risk.

The treatment of a patient with IA associated with AVM that has not bled should be well planned, judicious, and aimed at obliteration of both lesions, if possible. The inherent risks of microsurgical, endovascular, or radiosurgical intervention should be carefully weighed against the natural history of the disease, which is poorly understood. The treatment of IAs associated with BAVMs in a patient who presents with hemorrhage should be aimed at the symptomatic lesion. The aneurysm is almost always the culprit in patients presenting with SAH. If the bleeding source cannot be determined, both lesions should be treated simultaneously or the aneurysm treated first because of its theoretical higher risk of rerupture. There are currently no data to support targeted embolization of a Type III aneurysm as a single treatment modality, independent of rupture status.

\section{Acknowledgments}

We would like to thank Suzanne "Jorlam" Truex, medical illustrator, and Jerri Thomas, Neurosurgery Registrar, for their invaluable assistance in the creation of this manuscript.

\section{Disclosure}

The authors report no conflict of interest concerning the materials or methods used in this study or the findings specified in this paper.

Author contributions to the study and manuscript preparation include the following. Conception and design: Flores, Klinger, Rickert, Barnett, Batjer, Samson. Acquisition of data: Flores, Klinger, Samson. Analysis and interpretation of data: Flores, Klinger, Rickert, Barnett, Welch, Samson. Drafting the article: all authors. Criti- 
cally revising the article: all authors. Reviewed submitted version of manuscript: all authors. Approved the final version of the manuscript on behalf of all authors: Flores. Study supervision: Flores, Rickert, Samson.

\section{References}

1. Abud DG, Riva R, Nakiri GS, Padovani F, Khawaldeh M, Mounayer C: Treatment of brain arteriovenous malformations by double arterial catheterization with simultaneous injection of Onyx: retrospective series of 17 patients. AJNR Am J Neuroradiol 32:152-158, 2011

2. al-Rodhan NR, Sundt TM Jr, Piepgras DG, Nichols DA, Rüfenacht D, Stevens LN: Occlusive hyperemia: a theory for the hemodynamic complications following resection of intracerebral arteriovenous malformations. J Neurosurg 78:167-175, 1993

3. Almefty K, Spetzler RF: Arteriovenous malformations and associated aneurysms. World Neurosurg 76:396-397, 2011

4. Arieti S, Gray EW: Progressive multiform angiosis: association of a cerebral angioma, aneurysms and other vascular changes in the brain. Arch Neurol Psychiatry 51:182-189, 1944

5. Batjer HH, Devous MD Sr, Meyer YJ, Purdy PD, Samson DS: Cerebrovascular hemodynamics in arteriovenous malformation complicated by normal perfusion pressure breakthrough. Neurosurgery 22:503-509, 1988

6. Batjer H, Samson D: Arteriovenous malformations of the posterior fossa. Clinical presentation, diagnostic evaluation, and surgical treatment. J Neurosurg 64:849-856, 1986

7. Batjer H, Suss RA, Samson D: Intracranial arteriovenous malformations associated with aneurysms. Neurosurgery 18:2935, 1986

8. Boyd-Wilson JS: The association of cerebral angiomas with intracranial aneurysms. J Neurol Neurosurg Psychiatry 22: 218-223, 1959

9. Brown RD Jr, Wiebers DO, Forbes GS: Unruptured intracranial aneurysms and arteriovenous malformations: frequency of intracranial hemorrhage and relationship of lesions. J Neurosurg 73:859-863, 1990

10. Cockroft KM, Thompson RC, Steinberg GK: Aneurysms and arteriovenous malformations. Neurosurg Clin N Am 9:565576, 1998

11. Crowley RW, Ducruet AF, McDougall CG, Albuquerque FC: Endovascular advances for brain arteriovenous malformations. Neurosurgery 74 (Suppl 1):S74-S82, 2014

12. Cunha e Sa MJ, Stein BM, Solomon RA, McCormick PC: The treatment of associated intracranial aneurysms and arteriovenous malformations. J Neurosurg 77:853-859, 1992

13. da Costa L, Wallace MC, Ter Brugge KG, O'Kelly C, Willinsky RA, Tymianski M: The natural history and predictive features of hemorrhage from brain arteriovenous malformations. Stroke 40:100-105, 2009

14. Day AL, Friedman WA, Sypert GW, Mickle JP: Successful treatment of the normal perfusion pressure breakthrough syndrome. Neurosurgery 11:625-630, 1982

15. de Oliveira E, Tedeschi H, Raso J: Comprehensive management of arteriovenous malformations. Neurol Res 20:673683, 1998

16. Drake CG, Friedman AH, Peerless SJ: Posterior fossa arteriovenous malformations. J Neurosurg 64:1-10, 1986

17. Elhammady MS, Aziz-Sultan MA, Heros RC: The management of cerebral arteriovenous malformations associated with aneurysms. World Neurosurg 80:e123-e129, 2013

18. Fournier D, TerBrugge KG, Willinsky R, Lasjaunias P, Montanera W: Endovascular treatment of intracerebral arteriovenous malformations: experience in 49 cases. J Neurosurg 75: 228-233, 1991

19. Gabriel RA, Kim H, Sidney S, McCulloch CE, Singh V, Johnston SC, et al: Ten-year detection rate of brain arteriovenous malformations in a large, multiethnic, defined population. Stroke 41:21-26, 2010
20. Garcia-Monaco R, Rodesch G, Alvarez H, Iizuka Y, Hui F, Lasjaunias P: Pseudoaneurysms within ruptured intracranial arteriovenous malformations: diagnosis and early endovascular management. AJNR Am J Neuroradiol 14:315-321, 1993

21. Garzon-Muvdi T, Pradilla G, Bekelis K, Gailloud P, Tamargo RJ: Surgical management of infratentorial arteriovenous malformations, in Quinones-Hinojosa A (ed): Schmidek \& Sweet Operative Neurosurgical Techniques: Indications, Methods, and Results, ed 6. Philadelphia: Elsevier Saunders, 2012, pp 995-1001

22. Halim AX, Johnston SC, Singh V, McCulloch CE, Bennett JP, Achrol AS, et al: Longitudinal risk of intracranial hemorrhage in patients with arteriovenous malformation of the brain within a defined population. Stroke 35:1697-1702, 2004

23. Halim AX, Singh V, Johnston SC, Higashida RT, Dowd CF, Halbach VV, et al: Characteristics of brain arteriovenous malformations with coexisting aneurysms: a comparison of two referral centers. Stroke 33:675-679, 2002

24. Hauck EF, Welch BG, White JA, Purdy PD, Pride LG, Samson D: Preoperative embolization of cerebral arteriovenous malformations with onyx. AJNR Am J Neuroradiol 30:492-495, 2009

25. Hernesniemi JA, Dashti R, Juvela S, Väärt K, Niemelä M, Laakso A: Natural history of brain arteriovenous malformations: a long-term follow-up study of risk of hemorrhage in 238 patients. Neurosurgery 63:823-831, 2008

26. Heros RC, Korosue K, Diebold PM: Surgical excision of cerebral arteriovenous malformations: late results. Neurosurgery 26:570-578, 1990

27. Kalani MYS, Albuquerque FC, Fiorella D, McDougall CG: Endovascular treatment of cerebral arteriovenous malformations. Neuroimaging Clin N Am 23:605-624, 2013

28. Kano H, Kondziolka D, Flickinger JC, Park KJ, Parry PV, Yang HC, et al: Stereotactic radiosurgery for arteriovenous malformations, Part 6: multistaged volumetric management of large arteriovenous malformations. Clinical article. J Neurosurg 116:54-65, 2012

29. Kano H, Kondziolka D, Flickinger JC, Yang HC, Flannery TJ, Awan NR, et al: Stereotactic radiosurgery for arteriovenous malformations, Part 2: management of pediatric patients. Clinical article. J Neurosurg Pediatr 9:1-10, 2012

30. Kano H, Kondziolka D, Flickinger JC, Yang HC, Flannery TJ, Awan NR, et al: Stereotactic radiosurgery for arteriovenous malformations, Part 3: outcome predictors and risks after repeat radiosurgery. Clinical article. J Neurosurg 116:21-32, 2012

31. Kano H, Kondziolka D, Flickinger JC, Yang HC, Flannery TJ, Niranjan A, et al: Stereotactic radiosurgery for arteriovenous malformations, Part 4: management of basal ganglia and thalamus arteriovenous malformations. Clinical article. J Neurosurg 116:33-43, 2012

32. Kano H, Kondziolka D, Flickinger JC, Yang HC, Flannery TJ, Niranjan A, et al: Stereotactic radiosurgery for arteriovenous malformations, Part 5: management of brainstem arteriovenous malformations. Clinical article. J Neurosurg 116:4453,2012

33. Kano H, Kondziolka D, Flickinger JC, Yang HC, Park KJ, Flannery TJ, et al: Aneurysms increase the risk of rebleeding after stereotactic radiosurgery for hemorrhagic arteriovenous malformations. Stroke 43:2586-2591, 2012

34. Kano H, Lunsford LD, Flickinger JC, Yang HC, Flannery TJ, Awan NR, et al: Stereotactic radiosurgery for arteriovenous malformations, Part 1: management of Spetzler-Martin Grade I and II arteriovenous malformations. Clinical article. J Neurosurg 116:11-20, 2012

35. Kaptain GJ, Lanzino G, Do HM, Kassell NF: Posterior inferior cerebellar artery aneurysms associated with posterior fossa arteriovenous malformation: report of five cases and literature review. Surg Neurol 51:146-152, 1999 
36. Kim EJ, Halim AX, Dowd CF, Lawton MT, Singh V, Bennett $\mathrm{J}$, et al: The relationship of coexisting extranidal aneurysms to intracranial hemorrhage in patients harboring brain arteriovenous malformations. Neurosurgery 54:1349-1358, 2004

37. Kondo R, Matsumoto Y, Endo H, Miyachi S, Ezura M, Sakai $\mathrm{N}$ : Endovascular embolization of cerebral arteriovenous malformations: results of the Japanese Registry of Neuroendovascular Therapy (JR-NET) 1 and 2. Neurol Med Chir (Tokyo) 54:54-62, 2014

38. Kondziolka D, Nixon BJ, Lasjaunias P, Tucker WS, TerBrugge K, Spiegel SM: Cerebral arteriovenous malformations with associated arterial aneurysms: hemodynamic and therapeutic considerations. Can J Neurol Sci 15:130-134, 1988

39. Kumar K, Demeria DD, Verma A: Recombinant tissue plasminogen activator in the treatment of intraventricular hemorrhage secondary to periventricular arteriovenous malformation before surgery: case report. Neurosurgery 52:964-969, 2003

40. Lasjaunias P, Manelfe C, Chiu M: Angiographic architecture of intracranial vascular malformations and fistulas-pretherapeutic aspects. Neurosurg Rev 9:253-263, 1986

41. Lasjaunias P, Piske R, Terbrugge K, Willinsky R: Cerebral arteriovenous malformations (C. AVM) and associated arterial aneurysms (AA). Analysis of $101 \mathrm{C}$. AVM cases, with 37 AA in 23 patients. Acta Neurochir (Wien) 91:29-36, 1988

42. Laves W: Ein Fall von Angioma arteriali racemosum des Gehirnes im Bereiche der rechten Arter: Cerebri media, nebst einem Beitrag zur Frage der Entwicklung von Rankenangiomen im Gehirn. Jahrb Psychiatr Neurol 44:55, 1925

43. Lawton MT: Spetzler-Martin Grade III arteriovenous malformations: surgical results and a modification of the grading scale. Neurosurgery 52:740-749, 2003

44. Lawton MT, Kim H, McCulloch CE, Mikhak B, Young WL: A supplementary grading scale for selecting patients with brain arteriovenous malformations for surgery. Neurosurgery 66:702-713, 2010

45. Lv X, Li Y, Yang X, Jiang C, Wu Z: Characteristics of arteriovenous malformations associated with cerebral aneurysms. World Neurosurg 76:288-291, 2011

46. Lv X, Wu Z, Li Y, Yang X, Jiang C, Sun Y, et al: Endovascular treatment of cerebral aneurysms associated with arteriovenous malformations. Eur J Radiol 81:1296-1298, 2012

47. Marks MP, Lane B, Steinberg GK, Chang PJ: Hemorrhage in intracerebral arteriovenous malformations: angiographic determinants. Radiology 176:807-813, 1990

48. Marks MP, Lane B, Steinberg GK, Snipes GJ: Intranidal aneurysms in cerebral arteriovenous malformations: evaluation and endovascular treatment. Radiology 183:355-360, 1992

49. Mayfrank L, Rohde V, Gilsbach JM: Fibrinolytic treatment of intraventricular haemorrhage preceding surgical repair of ruptured aneurysms and arteriovenous malformations. Br $\mathbf{J}$ Neurosurg 13:128-131, 1999

50. McKissock W, Paterson JH: A clinical survey of intracranial angiomas with special reference to their mode of progression and surgical treatment: a report of 110 cases. Brain 79:233266, 1956

51. Meisel HJ, Mansmann U, Alvarez H, Rodesch G, Brock M, Lasjaunias P: Cerebral arteriovenous malformations and associated aneurysms: analysis of 305 cases from a series of 662 patients. Neurosurgery 46:793-802, 2000

52. Meisel HJ, Mansmann U, Alvarez H, Rodesch G, Brock M, Lasjaunias P: Effect of partial targeted N-butyl-cyano-acrylate embolization in brain AVM. Acta Neurochir (Wien) 144:879-888, 2002

53. Mjoli N, Le Feuvre D, Taylor A: Bleeding source identification and treatment in brain arteriovenous malformations. Interv Neuroradiol 17:323-330, 2011

54. Mohr JP, Parides MK, Stapf C, Moquete E, Moy CS, Overbey JR, et al: Medical management with or without interventional therapy for unruptured brain arteriovenous malformations
(ARUBA): a multicentre, non-blinded, randomised trial. Lancet 383:614-621, 2014

55. Morgan M: Therapeutic decision making, in Winn HR (ed): Youmans Neurological Surgery, ed 6. Philadelphia: Elsevier Saunders, 2011, Vol 4, pp 4034-4048

56. O'Shaughnessy BA, Getch CC, Bendok BR, Batjer HH: Microsurgical resection of infratentorial arteriovenous malformations. Neurosurg Focus 19(2):E5, 2005

57. Ogilvy CS, Stieg PE, Awad I, Brown RD Jr, Kondziolka D, Rosenwasser R, et al: AHA Scientific Statement: Recommendations for the management of intracranial arteriovenous malformations: a statement for healthcare professionals from a special writing group of the Stroke Council, American Stroke Association. Stroke 32:1458-1471, 2001

58. Okamoto S, Handa H, Hashimoto N: Location of intracranial aneurysms associated with cerebral arteriovenous malformation: statistical analysis. Surg Neurol 22:335-340, 1984

59. Ondra SL, Troupp H, George ED, Schwab K: The natural history of symptomatic arteriovenous malformations of the brain: a 24-year follow-up assessment. J Neurosurg 73:387391, 1990

60. Perata HJ, Tomsick TA, Tew JM Jr: Feeding artery pedicle aneurysms: association with parenchymal hemorrhage and arteriovenous malformation in the brain. J Neurosurg 80:631634, 1994

61. Perret G, Nishioka H: Report on the Cooperative Study of Intracranial Aneurysms and Subarachnoid Hemorrhage. Section VI: Arteriovenous malformations. An analysis of 545 cases of cranio-cerebral arteriovenous malformations and fistulae reported to the cooperative study. J Neurosurg 25:467-490, 1966

62. Piotin M, Ross IB, Weill A, Kothimbakam R, Moret J: Intracranial arterial aneurysms associated with arteriovenous malformations: endovascular treatment. Radiology 220:506-513, 2001

63. Pollock GA, Shaibani A, Awad I, Batjer HH, Bendok BR: Intraventricular hemorrhage secondary to intranidal aneurysm rupture-successful management by arteriovenous malformation embolization followed by intraventricular tissue plasminogen activator: case report. Neurosurgery 68:E581-E586, 2011

64. Redekop G, TerBrugge K, Montanera W, Willinsky R: Arterial aneurysms associated with cerebral arteriovenous malformations: classification, incidence, and risk of hemorrhage. J Neurosurg 89:539-546, 1998

65. Rinkel GJ, Djibuti M, Algra A, van Gijn J: Prevalence and risk of rupture of intracranial aneurysms: a systematic review. Stroke 29:251-256, 1998

66. Schwarz S, Schwab S, Steiner HH, Hacke W: Secondary hemorrhage after intraventricular fibrinolysis: a cautionary note: a report of two cases. Neurosurgery 42:659-663, 1998

67. Shenkin HA, Jenkins F, Kim K: Arteriovenous anomaly of the brain associated with cerebral aneurysm. Case report. J Neurosurg 34 (2 Pt 1):225-228, 1971

68. Spetzler RF, Martin NA: A proposed grading system for arteriovenous malformations. Clinical article. J Neurosurg 65: 476-483, 1986

69. Spetzler RF, Ponce FA: A 3-tier classification of cerebral arteriovenous malformations. Clinical article. J Neurosurg 114: 842-849, 2011

70. Spetzler RF, Wilson CB, Weinstein P, Mehdorn M, Townsend J, Telles D: Normal perfusion pressure breakthrough theory. Clin Neurosurg 25:651-672, 1978

71. Stapf C, Mast H, Sciacca RR, Choi JH, Khaw AV, Connolly ES, et al: Predictors of hemorrhage in patients with untreated brain arteriovenous malformation. Neurology 66:1350-1355, 2006

72. Starke RM, Komotar RJ, Hwang BY, Fischer LE, Otten ML, Merkow MB, et al: A comprehensive review of radiosurgery 


\section{B. C. Flores et al.}

for cerebral arteriovenous malformations: outcomes, predictive factors, and grading scales. Stereotact Funct Neurosurg 86:191-199, 2008

73. Stemer AB, Bank WO, Armonda RA, Liu AH, Herzig DW, Bell RS: Acute embolization of ruptured brain arteriovenous malformations. J Neurointerv Surg 5:196-200, 2013

74. Stewart RM, Ashby WR: Angioma arteriale racemosum in an acallosal brain: a clinical and pathological report. J Neurol Psychopathol 11:289-303, 1931

75. Taylor CL, Dutton K, Rappard G, Pride GL, Replogle R, Purdy PD, et al: Complications of preoperative embolization of cerebral arteriovenous malformations. J Neurosurg 100:810-812, 2004

76. Thompson RC, Steinberg GK, Levy RP, Marks MP: The management of patients with arteriovenous malformations and associated intracranial aneurysms. Neurosurgery 43:202-212, 1998

77. Turjman F, Massoud TF, Viñuela F, Sayre JW, Guglielmi G, Duckwiler G: Aneurysms related to cerebral arteriovenous malformations: superselective angiographic assessment in 58 patients. AJNR Am J Neuroradiol 15:1601-1605, 1994

78. van Beijnum J, van der Worp HB, Buis DR, Al-Shahi Salman R, Kappelle LJ, Rinkel GJ, et al: Treatment of brain arteriovenous malformations: a systematic review and meta-analysis. JAMA 306:2011-2019, 2011
79. Waga S, Itoh H, Kojima T: Posterior inferior cerebellar artery aneurysm associated with arteriovenous malformation fed by the same artery. Surg Neurol 23:617-620, 1985

80. Walsh FB, King AB: Ocular signs of intracranial sacuular aneurysms: experimental work on collateral circulation through the ophthalmic artery. Arch Ophthalmol 27:1-33, 1942

81. Wilkins RH: Natural history of intracranial vascular malformations: a review. Neurosurgery 16:421-430, 1985

82. Yu SCH, Chan MSY, Lam JMK, Tam PHT, Poon WS: Complete obliteration of intracranial arteriovenous malformation with endovascular cyanoacrylate embolization: initial success and rate of permanent cure. AJNR Am J Neuroradiol 25: 1139-1143, 2004

Manuscript submitted May 14, 2014.

Accepted June 26, 2014.

Please include this information when citing this paper: DOI: 10.3171/2014.6.FOCUS14165.

Address correspondence to: Bruno C. Flores, M.D., Department of Neurological Surgery, University of Texas Southwestern Medical Center, 5323 Harry Hines Blvd., Mail Code 8855, Dallas, TX 75390. email: bruno.flores@phhs.org. 